\title{
JOVENS CONCLUINTES DE ENSINO MÉDIO E O MERCADO DE TRABALHO
}

\author{
Geraldo Leandro Rocha Silva ${ }^{1}$ \\ Zionel Santana ${ }^{2}$
}

\begin{abstract}
RESUMO: A globalização da educação nacional, especificamente da escola, pode ser equiparada à promoção ou um espaço de habilidades e competências que possam formar cidadãos críticos, capazes de pensar e, ainda, de se profissionalizarem; motivou-se pela tendência internacional de países que, recentemente, modificaram seus sistemas educacionais, com propostas de currículos diferenciados, não deixando de visar soluções para a sociedade do capital em situação de crise (PIOLLI; SALA, 2020). Torna-se necessário o preparo de jovens concluintes que não têm interesse ou não têm condição do ingresso ao Ensino Superior, necessitando ingressar e ser aceito pelo mercado de trabalho. De acordo com Vilhena (2019), é preciso uma aproximação do Ensino Médio, enquanto representação da educação, para que os jovens estabeleçam laços de confiança e intensifiquem sua credibilidade neste veículo enquanto projeção para o futuro e para a conquista do mercado de trabalho. $\mathrm{O}$ tema vem de encontro às necessidades de capital humano no mercado de trabalho, com habilidades e competências para suprir as demandas empresariais. Já se motivava pelos indícios e testagens da reforma curricular e antes da sua regulamentação de obrigatoriedade de cumprimento do cronograma proposto; ou seja, antes da Portaria no. 521/21.A proposta deste estudo se justifica e se faz relevante pois, um currículo complementar social sugerido para profissionalização ou capacitação de jovens concluintes do Ensino Médio, por meio de desenvolvimento de habilidades e competências demandas para a melhoria de seu capital intelectual, pode representar o êxito para a empregabilidade daqueles que almejam o ingresso no mercado de trabalho.
\end{abstract}

Palavras-Chave: Habilidades. Competências. Mercado de Trabalho. Currículo. Empregabilidade. Novo Ensino Médio.

ABSTRACT:The globalization of national education, specifically the school, can be equated to the promotion or a space of skills and competences that can form critical citizens, capable of thinking and, also, of professionalizing themselves; it was motivated by the international trend of countries that recently changed their educational systems, with proposals for differentiated curricula, while aiming at solutions for the society of capital in crisis situations (PIOLLI; SALA, 2020). It is necessary to prepare young graduates who are not interested in or are unable to enter Higher Education, needing to enter and be accepted by the labor market.According to Vilhena (2019), it is necessary to bring high school closer together, as a representation of education, so that young people can establish bonds of trust and intensify their credibility in this vehicle as a projection for the future and for conquering the labor market. The theme meets the needs of human capital in the labor market, with skills and competences to meet business demands. It was already motivated by the evidence and tests of the curricular reform and before its mandatory regulation of compliance with the proposed schedule; that is, before Ordinance no. 521/21. The proposal of this study is justified and relevant because a complementary social curriculum suggested for the professionalization or training of young high school graduates, through the development of skills and competences required for the improvement of their intellectual capital, can represent the success for the employability of those who aspire to enter the labor market.

Keywords: Skills. Job market. Resume. Employability. New High School.

\footnotetext{
${ }^{1}$ Mestrando em Gestão, Planejamento e Ensino na UNINCOR. Professor de Contabilidade na Faculdade de Filosofia, Ciências e Letras de Boa Esperança NOVA FAFIBE. MBA em Gestão de Tributos e Planejamento Tributário pela UNINCOR, Sócio Administrador e Contador no Escritório - ROCHA ESPECIALISTA CONTÁBIL E TRIBUTÁRIO LTDA. Tem experiência de 25 anos na área de Contabilidade, atuando principalmente no seguinte tema: FISCAL, TRIBUTÁRIO. Graduado em Ciências Contábeis pela Faculdade Cenecista de Varginha - FACECA (2012). E-mail: rocha.contabil@hotmail.com.

${ }^{2}$ Doutorado em Filosofia. Professor no Programa de Mestrado Planejamento e Ensino do Centro Universitário do Vale do Rio Verde-Unincor.E-mail: zionel@unincor.edu.br.
} 


\section{INTRODUÇÃO}

O tema do projeto é o Ensino Médio e o mercado de trabalho, onde analisaremos se os jovens concluintes de ensino médio estão preparados para o mercado de trabalho. A partir desta análise coloca-se sob suspeita que o currículo do Ensino Médio Público não se encontra estruturado para promover desenvolvimento de habilidades e competências necessárias aos jovens concluintes desta etapa da Educação Básica que se interessam pelo ingresso no mercado de trabalho, dificultando sua empregabilidade. Parte-se do seguinte problema e pesquisa: o currículo do Ensino Médio Público é condizente e promove o desenvolvimento de habilidades e competências para jovens concluintes desta etapa da Educação Básica, dando-lhes condição de igualdade para concorrência e empregabilidade?

O Ensino Médio constitui-se em uma etapa de múltiplas funções, voltada para a formação integral do indivíduo em sua juventude. O Ensino Médio engloba a proposta de consolidação de conhecimentos e habilidades básicas dos jovens, preparando-os para o ingresso no ensino superior ou no mercado de trabalho, sem o descuido de educá-los enquanto cidadãos capazes de agir de forma íntegra e em convivência harmônica com a sociedade (TARTUCE et al., 2018; VILHENA, 2019).

Teoricamente, a Lei de Diretrizes e Bases da Educação Nacional (LDB) - Lei noo. 9394/1996 (BRASIL, 1996) - associa o processo 'educativo' do Ensino Médio (ao caracterizá-lo) ao contexto e às mudanças do mercado de trabalho. Frigotto (2005), em obra sobre concepções e mudanças no mundo do trabalho e o Ensino Médio, associa o período da 'educação' com o período de constituição de relações sociais e embasamentos para o processo produtivo.

Na prática, ao final do Ensino Médio, o jovem é obrigado a fazer escolhas (ou não) pela continuação de sua formação, tendo em destaque o Ensino Superior ou o mercado de trabalho (OLIVEIRA, 2018).

Especificamente, em relação ao ingresso no mercado de trabalho, a educação recebida no Ensino Médio configura-se como elemento discriminador ao mesmo tempo que discriminatório, considerando que vem sempre dividir social, econômica e politicamente os sujeitos da sociedade. Assim, sujeitos têm emprego (ou não) a partir de sua categorização como educados/formados (ou não), a partir da aptidão das habilidades e competências exigidas pelo mercado de trabalho e contempladas (ou não) no Ensino Médio (OLIVEIRA, 2018).

Os jovens concluintes do Ensino Médio nem sempre estão conscientes das dificuldades que serão encontradas para ter acesso ao mercado de trabalho, como a concorrência ou a necessidade de aprimoramento de habilidades e competências exigidas pelo mundo globalizado (SOUZA; VAZQUEZ, 2015). Nesse sentido, percebe-se que estes jovens optantes ou demandantes pelo ingresso no mercado de trabalho, em sua maioria, apresentam expectativas diferenciadas em relação à realidade da competitividade, haja vista a não acolhida imediata ou a não receptividade do próprio mercado por essa clientela que chega despreparada (VILHENA, 2019).

Tais assertivas asseguram a premissa de que a grade curricular exigida a estes educandos os remetem para a continuidade do ensino - ou seja, o acesso ao Ensino Superior -, estando bem distanciada da demanda de jovens que vão ingressar ao mercado de trabalho (SOUZA; VASQUES, 2015). As habilidades e competências exigidas pelo mercado de trabalho não são contempladas e efetivadas aos alunos de Ensino Médio 
como parâmetro competitivo. Assim, o conceito de educação a estes jovens requer olhares mais definidos sobre o mercado de trabalho, principalmente no que tange o currículo escolar.

Entretanto, não se pode desconsiderar que a reforma do Ensino Médio (BRASIL, 2017) está prestes à sair da teoria e ser colocada em prática de forma obrigatória. O ditame é que, a partir do ano de 2022, em todas as escolas (públicas e privadas), comece o $\mathrm{I}^{\circ}$ ano do Ensino Médio com um novo formato, alinhando-se aos conteúdos da Base Nacional Comum Curricular (BNCC). A implementação está regulamentada pelo cronograma do Novo Ensino Médio (NEM), instituída pela Portaria n.521 em 13 de julho de 2021 do Ministério da Educação (MEC), publicada no Diário Oficial da União (BRASIL, 202I).

A reestruturação está prevista para o período de 2022-2024, sendo que o modelo provisiona alterações na grade curricular e na carga horário no ciclo, dando permissão para que os jovens possam escolher seus caminhos em relação às áreas específicas e formação técnica e profissional (SOARES; SIMÕES, 202I) - o que, provavelmente amplia suas chances de inserção no mercado de trabalho, haja vista a concessão de formação para a competitividade (RIBEIRO; ARRUDA; BOMFIM, 202I). A possibilidade de escolha é a materialização da construção de um currículo adequado e uma forma de escuta dos jovens e, por isso, consequência para uma ressignificação do conhecimento e do processo de ensino e aprendizagem. Além disso, sistematiza a regionalização do currículo (OBSERVATÓRIO DE EDUCAÇÃO, ENSINO MÉDIO E GESTÃO, 202I).

Para o Ministério da Educação, a reestruturação implica em ampliar conhecimentos em áreas de interesses dos jovens, sendo que as propostas de itinerários formativos oportunizam as trilhas de aprofundamento ou aperfeiçoamento (PIOLLI; SALA, 2020). Aumentar a carga horária e o tempo dos jovens na escola são pontos destacados para configuração do protagonismo da aprendizagem, considerando que os jovens vão aprender o exercício da criticidade e do pensamento, o que os permite se posicionarem mais ativos e prontos para escolhas acadêmicas e profissionais (RIBEIRO; ARRUDA; BOMFIM, 202I). Por isso, diz-se que o Novo Ensino Médio ocupa-se do desenvolvimento do projeto de vida dos jovens, sendo espaço para reflexão em relação ao presente e almejo de futuro; espaço para promoção do autoconhecimento, da desenvoltura de suas identidades, autonomia e escolhas assertivas, pautadas em habilidades e competências desenvolvidas (ALMEIDA; CARVALHO, 2021).

Contudo, enquanto comprovações empíricas não acontecem para firmar o NEM, busca-se, então, a identificação das habilidades e competências exigidas pelo mercado de trabalho para confrontar com a grade curricular do atual Ensino Médio (perante análise de suas principais disciplinas) para a proposição de um currículo complementar social (enquanto produto tecnológico) para preparar (capacitar e habilitar) os alunos concluintes desta etapa da educação básica para o mercado de trabalho.

Para tanto, opta-se por uma pesquisa do tipo aplicada exploratório-explicativa, com abordagem qualitativa utilizando-se de pesquisa bibliográfica e estudo de caso como formas de coleta de dados. Desta forma, pode-se afirmar que o caso em estudo envolve a análise do currículo do Ensino Médio e jovens da etapa final desta etapa básica de uma escola pública do município de Três Pontas-MG - sujeitos estes disponíveis para avaliação de conhecimentos prévios e aplicação de uma cartilha de uma cartilha elabora que trabalhe noções de Contabilidade para o Ensino Médio (e por isso, está associado à uma observação participante de seu pesquisador, haja vista a formação e expertise da sua autoria, enquanto profissional desta área), a partir das habilidades e competências pertinentes à disciplina de Matemática, para auxiliar na preparação para a 
profissionalização e enfrentamento em igualdade do mercado de trabalho.

\section{REFERENCIAL TEÓRICO \\ 2.I Educação, Ensino Médio, currículo e mercado de trabalho}

O início da década de 90 representa um marco divisório acerca das publicações de estudos e trabalhos nacionais e internacionais relacionados à relevância das transformações nos processos educativos em prol da formação de um perfil diferente de trabalhador (ESPINDULA; LEITE; PEREIRA, 2012). Estes estudos e trabalhos, de modo generalizado, referenciavam o processo de reestrutura produtiva e globalizada da economia, enaltecendo um perfil inovador de trabalhador demandado pelo setor produtivo da sociedade (OLIVEIRA, 2015). Enalteciam que a forma singular para que a escola se posiciona atualizada em contribuição ao novo cenário imputaria uma reestrutura de suas práticas e arranjos curriculares, enquanto direcionamento do preparo de seus educandos, do desenvolvimento de competências enquanto estratégia para adquirir novas capacidades, garantidoras do acesso e permanência no mercado de trabalho (OLIVEIRA, 2018).

No Brasil, a discurssividade disseminada da empregabilidade orientou, pelo menos teoricamente, as práticas do sistema de ensino público, instaurando-se como referencial para ações governamentais destinadas à qualificar profissionalmente os educandos (SILVA; SCHEIBE, 2017).

$\mathrm{Na}$ esfera empresarial, adotou-se uma discursividade que representou uma imposição de escolas básicas de melhores qualidades ao poder público (OLIVEIRA, 2005). Na ocasião, agentes da economia asseguravam que a péssima qualidade da educação básica seria a responsável pela imposição do desenvolvimento de práticas formativas complementares aos alunos - principalmente, aqueles egressos de escolas públicas - cabíveis aos empresários empregadores, o que lhes imputava em gastos e impactos na competitividade de seus produtos em detrimentos aqueles similares estrangeiros (MACIEL; JACOMELI; BRASILEIRO, 2017).

Se fez consensual a demanda pela reformulação do sistema educacional, que foi se fortalecendo aos poucos, emergindo o contexto de escola de qualidade (RAMOS, 2014). Na ocasião, a má qualidade, especificamente do Ensino Médio, era reconhecida tanto pelos altos índices de reprovação (consequentemente, pelos baixos níveis de aprendizagem dos egressos), quanto pelo abandono da escola (RODRIGUES, 2019). Este mapeamento comprovou o que Frigotto (1989) já destacava como a produtividade da escola improdutiva, 
reconhecendo precocemente a necessidade da repensar e revisar a relação existente entre a educação, a estrutura econômica social e capitalista.

Para Ciavatta e Ramos (20II), foi unanime a concepção de que a escola não garantia a aprendizagem dos conteúdos curriculares, que por consequência não auxiliava os jovens do Ensino Médio na aquisição da melhor qualificação que lhes garantissem a inserção no mercado de trabalho. Ferreti (2018) corrobora com este pensamento, destacando que além da má qualidade do Ensino Médio da escola pública, proporcionando pouca atratividade aos jovens e motivando-os à evasão, o crescimento do desemprego para a parcela jovem da população se fez desafio para o governo. Pochmann (2008) assegura que, em termos práticos, este problema do desemprego veio culminar como um temor social em decorrência do temor educacional. Foi a partir de tal advento que jovens passaram a ser protagonistas da violência e do tráfico de drogas instaurados na sociedade.

Assim, a inaptidão da escola em garantir integração e inserção do jovem no mercado de trabalho, impondo aos governantes a elaboração de novas estratégias e políticas públicas para minimização deste impacto e das consequências negativas promovidas pelo modelo econômico centrado na probidade da mão de obra se fizeram inquestionáveis (FERRETI, 2018).

Gentili (1999), destacou a temática enunciando a educação como desintegradora e como promessa para o desemprego e Frigotto (1999) enunciando a educação como responsável pela crise no trabalho. E, segundo Ferreti (2018), a implementação de políticas públicas destinadas aos jovens, garantidoras de formação profissional para o mercado de trabalho, foi a solução emergencial encontrada para tentativa de reversão daquele contexto.

De acordo com Oliveira (2018), a reversão deste quadro de tensões - ou seja, a redução da violência, o aumento da garantia e acesso à escola - foram metas que embasaram ações governamentais das décadas seguintes, visando a perspectiva de futuro para a juventude brasileira, por meio de implementação de programas visando a qualificação profissional dos jovens.

[...] dentre os quais se destacam, no governo Fernando Henrique Cardoso (FHC), o Plano Nacional de Qualificação do Trabalhador (Planfor); no governo Lula, o Programa Nacional de Qualificação (PNQ) e, no governo Dilma, o Programa Nacional de Acesso ao Ensino Técnico e Emprego (Pronatec). Mais recentemente, durante os governos do presidente Lula e da presidenta Dilma Roussef, listamos alguns programas que colocaram a questão da qualificação profissional como um dos seus eixos centrais: Programa Nacional de Inclusão de Jovens (Projovem), Programa Nacional de Estímulo ao Primeiro Emprego (PNPE), Programa de Integração de Educação Profissional ao Ensino Médio na Modalidade de Educação 
de Jovens e Adultos (Proeja), Programa Escola de Fábrica [...] (OLIVEIRA, 2018, p.2).

Para Ferreti (2018), considerando a evolução dos programas visando a qualificação profissional dos jovens, percebe-se que as ações propostas culminam para uma contrarreforma do Ensino Médio para tal garantia e, por isso, discussões acerca da contribuição da escola para a inserção dos jovens no mercado de trabalho se fizeram pautas repetitivas e exaustivas.

Consensualmente, existe uma afirmativa da existência de uma crise instaurada entre a escola e os jovens do Ensino Médio, pois estes colocam sob suspeita a influência da educação em seus projetos de vida, considerando que esta instituição marca-se como nada significativa para o presente e, consequentemente negativa para o futuro. É consensual, ainda, a afirmativa de que principalmente as escolas públicas do Ensino Médio, não consideram que os jovens tenham histórias próprias para além de seus muros (GONÇALVES, 20I7; FERRETI; SILVA, 20I7; LINO, 20I7; KRAWCZYK; FERRETTI, 2017; OLIVEIRA; BATISTA, 2018; ANDRADE; SOUZA, 2020).

Assim, tanto pela desigual promoção e distribuição do conhecimento, quanto pelo empobrecimento do currículo com lacunas de conteúdos que explorem competências e habilidades, reforçam-se mecanismos que visam impor aos jovens do Ensino Médio público o acesso aos postos de trabalho precarizados (GONÇALVES, 2017).

Esta garantia da precarização de trabalho à esta clientela específica já era alertada por Frigotto (1989), quando evidenciou a baixa qualidade da escola, culminando no Ensino Médio, servindo à acumulação capitalista.

A estrutura curricular do Ensino Médio promove a formação de jovens de forma limitada, garantindo somente o domínio de conteúdos que lhes garantam uma qualificação básica. Isto permite uma interpretação da existência da distribuição desigual dos conhecimentos acumulados, justamente pela péssima qualidade da formação desenvolvida - sustentando mecanismos excludentes, uteis à acumulação do capital e fomentos de postos de trabalhos precários para jovens (OLIVEIRA: BATISTA, 20I8). A educação do Ensino Médio de baixa qualidade, sustentada por um currículo que não contempla o desenvolvimento de habilidades e competências essenciais para acesso desta classe desfavorecida ao mercado de trabalho mais igualitário, fortalece os modelos de acumulação (OLIVEIRA, 2015; OLIVEIRA, 2018).

A inserção no mercado de trabalho mais elitizado, que beneficia uma classe que pode 
ter acesso ao Ensino Superior, se faz uma extensão direta do processo de escolarização básica e qualificação do profissional jovem. Contudo, para os jovens de classe mais baixa, oriundos da escola pública, o Ensino Médio seria a oportunidade ímpar para aquisição de conhecimentos mínimos demandados pelo mercado de trabalho e, então, quaisquer ações que restrinjam este acesso sustentam e ampliam a desigualdade social (FERRETTI; SILVA, 2017); ampliam e sustenham a precarização intensificada pelo neoliberalismo, voltada à flexibilização dos direitos trabalhistas. (KRAWCZYK; FERRETTI, 2017).

Andrade e Souza (2020) afirmam que, na atualidade, o Ensino Médio caracteriza-se por um currículo extenso, fragmentado e superficialmente organizado; um currículo que não promove diálogo com os jovens, nem tampouco com o setor produtivo, negligenciando as demandas do século XXI, pois dificulta o acesso aos conteúdos demandados pela formação cidadã - consequentemente, social.

Oliveira (2018) aponta este currículo como promotor de jovens que sairão do Ensino Médio sem autonomia e criticidade; que sonega conhecimentos e precária e empobrece a formação escolar.

Ferreti e Silva (2017) e Ferreti (2018) enxergam na proposição de currículos complementares formas mais atrativas e flexíveis para que os jovens concluintes do Ensino Médio se prontifiquem como profissionalmente capacitados para o mercado de trabalho. Os mesmos autores repudiam a extensão do currículo e a organização de sua grade curricular, justificando-os como responsáveis pelos altos índices desfavoráveis para esta etapa da Educação Básica nas avaliações promovidas.

Consensualmente, tem-se a assertiva de que este currículo atual é excludente, e não vem favorecer a aprendizagem de qualidade, não sendo capaz de desenvolver habilidades e competências tão demandadas pelos jovens, principalmente os mais carentes, frustrando-os em seus projetos de vida e iludindo-os em suas propostas de inserção no mercado de trabalho, sustentando um modelo de estratificação social arcaico e ainda muito comum na sociedade brasileira (GONÇALVES, 2017; FERRETI; SILVA, 2017; LINO, 2017; KRAWCZYK; FERRETTI, 2017; OLIVEIRA; BATISTA, 2о18; ANDRADE; SOUZA, 2020).

De acordo com Moran (2017), o projeto de vida retrata aquilo que, no caso o jovem do Ensino Médio, pretende ser/fazer em momentos futuros de sua vida, bem como a definição das formas para conquista do pretendido. Materializa a consciência e as forma de avaliar e trilhar aprendizados, aquisição de conhecimentos, formação e desenvolvimento de 
competências e habilidades. Resume-se em um exercício multidimensional e constante para dar visibilidade às descobertas e escolhas, aos valores, aos ganhos e às perdas, construções e revisões, mudanças e adaptações, sempre pensando em desafios futuros ao longo da vida um exercício de erros e acertos, de criação de cenários de curto e médio prazo.

Ainda, para Moran (2017), o projeto de vida deve inserir-se em contextos reflexivos, em vivências individualizadas, da mesma forma em que coletivas, sempre contemplando a compreensão das diferenças e autonomia. Para tanto, pode ser desenvolvido a partir de 3 dimensões: "pessoal (identidade, aprender a ser): autoconhecimento e autocuidado; social (eu com o mundo, aprender a conviver, cidadania): empatia; profissional (aprender a fazer): desenvolvimento de habilidades e competências relacionadas ao mundo do trabalho" Moran (2017 p.I).

Considerando que a dimensão profissional do jovem do Ensino Médio é a que interessa para o presente projeto de pesquisa, pode-se afirmar com base nos ensinamentos de Moran (2017), que sua escolha assertiva condiciona-se e se conecta junto às duas outras dimensões, pois são contributivas para o autoconhecimento, para a autonomia e para a percepção de mundo, sendo essenciais quando a pretensão é o reconhecimento das diversas possibilidades para a trajetória de sua carreira - que no caso, competividade no mercado de trabalho e empregabilidade.

\subsection{A Base Nacional Curricular Comum, o currículo do Novo Ensino Médio e o preparo do jovem para o mercado de trabalho}

A Base Curricular Nacional Comum (BNCC) veio nortear a gestão educacional no Brasil, objetivando balizar a educação básica, estabelecendo níveis de aprendizagem e de conhecimento demandados, inclusive para os jovens do Ensino Médio. Simboliza, então, a resultante de debates exaustivos e culminância de outras regulamentações, estabelecendo o rompimento com a verticalidade do currículo, passando a valorizar a inclusão dos jovens estudantes na construção de seus conhecimentos, e para a condução de seus projetos de vida e, por isso, promotora de habilidades e consequências que lhes garantam o título de cidadãos críticos, ativos/autônomos e reflexivos (PIOLLO; SALA, 2020).

A Base veio desmistificar um arranjo curricular com predomínio de um conjunto de disciplinas pré-estabelecidas, do repasse do conhecimento pronto aos alunos, derrubando a aprendizagem vertical, rompendo com a decisão do Estado em distribuir conteúdo construídos para alunos como simples receptores (ALMEIDA; CARVALHO, 202I). 
Como ponderado pelo Observatório de Educação, Ensino Médio e Gestão (202I), com a BNCC, o modelo vertical cedeu espaço para a centralização do jovem do Ensino Médio na construção do seu conhecimento e, desta forma, influenciador de seu contexto social. $O$ processo de acumulação de informações desocupa o espaço para o processo dinâmico de construção de contextos. Foi na proposta de construção de contextos que as particularidades de cada região/município/comunidade escolar fizeram parte do processo de gestão das escolas, sendo possível trazer para dentro do seu âmbito (e para a proposta de seu currículo), questões relevantes sobre o entorno da escola e a realidade vivida pelos jovens alunos.

A BNCC baliza a qualidade da aprendizagem no país, com a tentativa de um padrão mais flexível e livre de engessamentos, considerando a autonomia de secretarias (estaduais e municipais) de educação e da gestão escolar para a proposição de currículos adequados, oportunos e próprios para atender às particularidades de cada contexto (RIBEIRO; ARRUDA; BOMFIM, 202I).

A desmistificação da verticalidade curricular se deu quando o documento prevê a qualidade da educação pautada no desenvolvimento das competências trazidas, sendo definidas como uma mobilização do conhecimento, das habilidades, das atitudes e valores necessários para a resolução de demandas complexas da vida cotidiana, com promoção da cidadania e do mundo do trabalho - por isso, diz-se que as competências estejam além de uma educação conteudista e pautada somente em disciplinas (SOARES; SIMÕES, 202I).

A proposta pedagógica de inclusão do jovem do Ensino Médio como agente ativo da construção de seu conhecimento desbanca sua condição de receptor de informações e o potencializa como promotor de seu projeto de vida, sendo a educação preconizadora de demandas da juventude e do adequado preparo de jovens para o enfrentamento dos desafios atuais (OBSERVATÓRIO DE EDUCAÇÃO, ENSINO MÉDIO E GESTÃO, 202I). Nessa perspectiva, a BNCC estreita relação com a proposta do Novo Ensino Médio, resguardado pela Lei $\mathrm{n}^{\mathrm{o}}$ 13.415/2017, que altera esta etapa da educação, fortalecendo e valorizando o projeto de vida (acadêmico ou profissional) do jovem protagonista da construção de seu conhecimento (BRASIL, 2017).

E, dentro da nova redação da Lei de Diretrizes e Base (LDB), emerge um protagonismo para a construção do conhecimento, dito como itinerários formativos do jovem do Ensino Médio, fortalecido pela proposta de um novo currículo pautado na BNCC: 
Curricular e por itinerários formativos, que deverão ser organizados por meio da oferta de diferentes arranjos curriculares, conforme a relevância para o contexto local e a possibilidade dos sistemas de ensino, a saber:

I - linguagens e suas tecnologias;

II - matemática e suas tecnologias;

III - ciências da natureza e suas tecnologias;

IV - ciências humanas e sociais aplicadas;

$\mathrm{V}$ - formação técnica e profissional (BRASIL, 2017, p.I).

O Novo Ensino Médio e a BNCC convidam para a associação da propedêutica tradicional de aprendizagem caracterizada pela interdisciplinaridade e junto às novas competências, possibilitando caminhos para jovens do Ensino Médio no que tange o aperfeiçoamento de conhecimentos que desejarem e compreenderem como mais relevantes para a suas formações e projetos de vida, por meio dos itinerários formativos - ou seja, resumidamente, pela parte flexível do currículo (OBSERVATÓRIO DE EDUCAÇÃO, ENSINO MÉDIO E GESTÃO, 2021).

O Sindicato dos Estabelecimentos de Ensino do Rio de Janeiro (SINEPE RIO, 202I), em parceria com a Federação Nacional das Escolas Particulares (FENEP), elaborou uma cartilha no final do mês de julho de 202I, posterior à publicação da Portaria n. 52I/2I do Diário Oficial da União, com direcionamentos do Novo Ensino Médio para 2022. Nesta os itinerários formativos são definidos de uma forma mais completa:

\footnotetext{
Itinerários formativos é um conjunto de situações e atividades educativas que os estudantes podem escolher conforme seu interesse, para aprofundar e ampliar aprendizagens em uma ou mais áreas do conhecimento e/ou na formação técnica e profissional $[\ldots]$.

É um percurso formativo do aluno e parte indissociável do currículo do Novo Ensino Médio; um conjunto de unidades curriculares ofertadas pelas instituições e redes de ensino que possibilitam ao estudante aprofundar seus conhecimentos e se preparar para o prosseguimento de estudos ou para o mundo do trabalho de forma a contribuir para a construção de soluções de problemas específicos da sociedade.

[...] portanto, os itinerários têm como na Universidade e/ou no mundo do trabalho (SINEPE RIO, 2021, p.2-3).
}

O Sinepe Rio (2021), a partir da definição de dos objetivos dos itinerários formativos, materializou o conceito associando-o a um guarda-chuva, 'cobrindo' projetos de vida, trilhas de aprofundamento e unidades curriculares eletivas - como mostra a Figura I 
Figura I - Itinerário Formativo Guarda-chuva

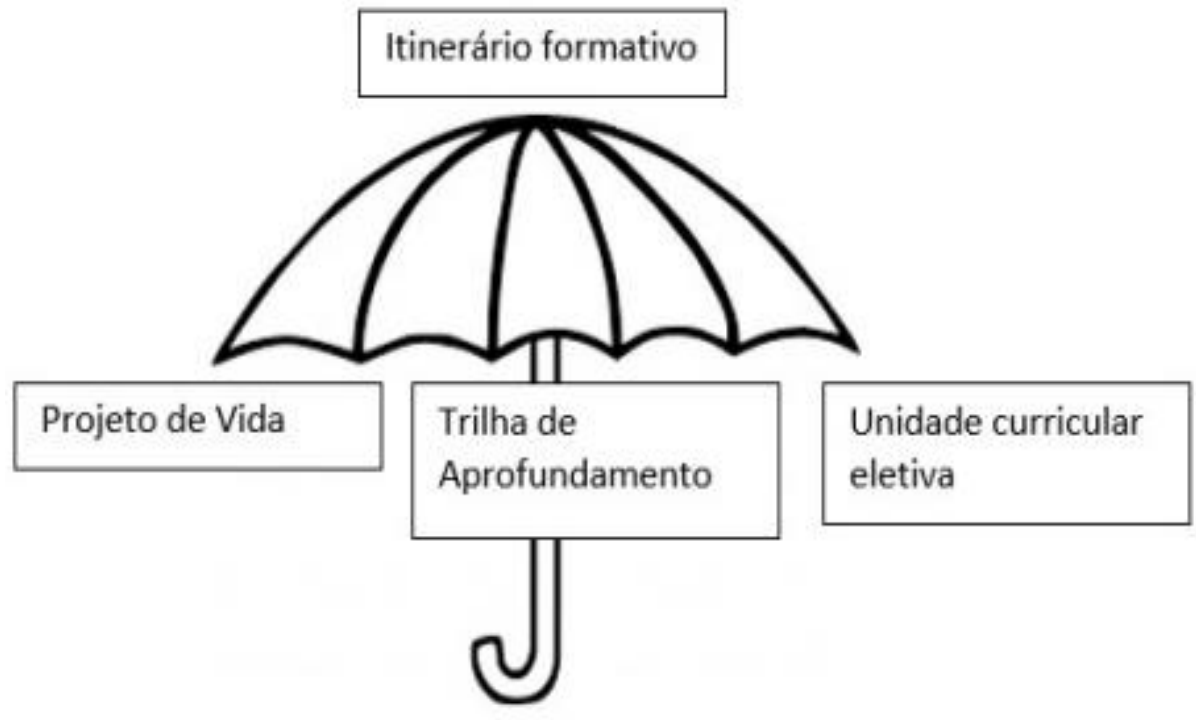

Fonte: Sinepe Rio (2021, p.4)

A explicação das 3 áreas englobadas pelo do itinerário formativo guarda-chuva da referida figura, pode ser organizada no Quadro I.

Quadro I - Itinerários formativos guarda-chuva

\begin{tabular}{|l|l|}
\hline $\begin{array}{l}\text { Trilhas } \\
\text { Aprofundamento de }\end{array}$ & $\begin{array}{l}\text { Podem contemplar determinadas áreas de atuação profissional, } \\
\text { integrando duas ou mais áreas do conhecimento ou, ainda, } \\
\text { contemplar a educação técnica profissional. } \\
\text { Podem ter uma ou mais unidades curriculares dentro delas, com } \\
\text { periodicidade semestral e devem ser escolhidas por cada escola em } \\
\text { função de sua identidade, vocação institucional e interesse de } \\
\text { público que atende. }\end{array}$ \\
\hline Projeto de Vida & $\begin{array}{l}\text { Tem por objetivo proporcionar reflexões de autoconhecimento e } \\
\text { favorecer o amadurecimento das visões de si e do vir a ser de cada } \\
\text { sujeito. } \\
\text { O trabalho pedagógica neste componente deve priorizar o } \\
\text { desenvolvimento integral dos estudantes ampliando suas } \\
\text { dimensões: pessoal, cidadã e profissional. }\end{array}$ \\
\hline
\end{tabular}




\begin{tabular}{|l|l|}
\hline Unidades & $\begin{array}{l}\text { Atuam como oportunidade de ampliação e diversificação das } \\
\text { trajetórias escolares e das aprendizagens, devendo ser de livre } \\
\text { escolha do estudante alinhar-se ao seu projeto de vida, de acordo } \\
\text { com as possibilidades de oferta das instituições ou das redes de } \\
\text { ensino. } \\
\text { Podem estar dentro da mesma trilha ou podem experimentar } \\
\text { componentes de diversas áreas e, a partir desta experiência, } \\
\text { encontrar subsídios e segurança para decidir sobre os } \\
\text { aprofundamentos a percorrer na } 2^{\mathrm{a}} \text { e na } 3^{\mathrm{a}} \text { séries. }\end{array}$ \\
\hline
\end{tabular}

Fonte: Sinepe Rio (2021, p.4, adaptado)

Os objetivos dos itinerários formativos são destacados pelo Observatório de Educação, Ensino Médio e Gestão (2021) como: aprofundar e ampliar aprendizagens (competências gerais, áreas do conhecimento e/ou formação técnica e profissional); consolidar formação integral (desenvolvimento de autonomia para realização dos projetos de vida); promover valores universais (ética, liberdade, democracia, justiça social, pluralidade, solidariedade e sustentabilidade); desenvolver habilidades (visão de mundo ampla e heterogênea, capacidade de tomar decisões e agir).

Os itinerários formativos que podem ser ofertados pelas escolas são 5 : Linguagens e suas Tecnologias; Matemática e suas Tecnologias; Ciências Humanas e Sociais Aplicadas;

Ciências da Natureza e suas Tecnologias; e Formação Técnica e Profissional. Além disso, de acordo com a proposta do Novo Ensino Médio, os itinerários formativos são atravessados por eixos estruturantes, sendo eles 4: Investigação Científica; Processos Criativos; Mediação e Intervenção Sociocultural e; Empreendedorismo (OBSERVATÓRIO DE EDUCAÇÃO, ENSINO MÉDIO E GESTÃO, 2021).

\section{METODOLOGIA}

Para o cumprimento dos objetivos de pesquisa elencados, opta-se por uma pesquisa do tipo aplicada, que segundo Zanella (2011), objetiva propor soluções aos problemas humanos, na tentativa de compreender como lidar com os mesmos. Assim, se colocada em prática, a pesquisa potencialmente irá contribuir com o apontamento de novos fatos para que novas pesquisas sejam desenvolvidas.

A pesquisa aplicada apoia-se em um referencial teórico que embasa as análises da realidade a ser estudada (ZANELLA, 20II) - que no caso, a realidade é o currículo do Ensino Médio Público, que não se faz condizente e promove o desenvolvimento de habilidades e competências para jovens concluintes desta etapa da Educação Básica, dando-lhes condição 
de igualdade para concorrência e empregabilidade.

Quanto ao objetivo, a pesquisa é exploratório-explicativa, pois: busca a ampliação do conhecimento à respeito de um fenômeno, explorando sua realidade e centra-se na preocupação da identificação de fatores determinantes no desencadeamento deste fenômeno, desta realidade, situando seu ambiente social de ocorrência, identificando sua causa e efeito (ZANELLA, 2oir) - que no caso, objetiva a identificação das habilidades e competências exigidas pelo mercado de trabalho, propor uma estrutura curricular complementar social (enquanto produto tecnológico) para preparar (capacitar e habilitar) os alunos concluintes do Ensino Médio para o mercado de trabalho.

Portanto, quanto à abordagem, a pesquisa se classifica como qualitativa, pois não faz uso de instrumentais estatísticos para a análise dos dados, tendo como base a cientificidade dos conhecimentos teórico-empíricos (ALYRIO, 2009).

Em relação aos procedimentos adotados para a coleta de dados, utiliza-se tanto da pesquisa bibliográfica - contando com fontes bibliográficas permissivas à cobertura ampliada do fenômeno em estudo para a busca de resposta ao problema de pesquisa formulado (ALYRIO, 2009) -, quanto de um estudo de caso - buscando profundidade na compreensão de um grupo específico em um contexto determinado (ZANELLA, 2oII). Assim, a pesquisa bibliográfica sobre o currículo atual do Ensino Médio Público e suas habilidades e competências para jovens concluintes desta etapa da Educação Básica se completa com um estudo de caso para verificação da conformidade (ou não) na condição de igualdade para concorrência e empregabilidade.

Entretanto, considerando o recorte temporal que envolve o tema de pesquisa deste projeto, não pode-se esquivar de uma abordagem bibliográfica, mesmo que ainda não esteja em vigor, sobre a proposta do NEM, contemplando seus itinerários formativos, que abarcam as habilidades e as competências da BNCC, que preparam os jovens para seus projetos de vida, para o mercado de trabalho e para a empregabilidade.

Foi feito um estudo de caso em uma escola das quatro escolas do município de Três Pontas-MG, e pode-se afirmar que o caso em estudo envolve a análise do currículo atual do Ensino Médio e jovens da etapa final desta etapa básica de uma escola pública - sujeitos estes disponíveis para avaliação de conhecimentos prévios e aplicação de uma cartilha de uma cartilha elabora que trabalhe noções de Contabilidade para o Ensino Médio, a partir das habilidades e competências pertinentes à disciplina de Matemática, para auxiliar na 
preparação para a profissionalização e enfrentamento em igualdade do mercado de trabalho.

A escolha da escola do estudo de caso foi devido ao fácil acesso da comunidade, por ser uma escola referência no município, com alunos do Ensino Fundamental e Médio a qual trabalhei por 13 anos.

O estudo foi feito com os alunos do Ensino Médio, nos utilizando das disciplinas português e matemática e com o apoio das Especialistas de Educação Básica à distância via google meet.

Além disso, tanto para a coleta, quanto para a análise dos dados, a pesquisa conta, ainda, com uma observação participante, haja vista a formação e expertise da sua autoria, enquanto profissional da Contabilidade. Foram feitas entrevistas com os alunos, professores, especialistas de educação à distância via google meet devido à pandemia. De acordo com Zanella (20II), na observação participante o pesquisador além de espectador do estudo, coloca-se em posição destacada junto ao fenômeno observado, pois sua familiaridade e vivencia direta relacionada à situação observada lhes conferem uma compreensão em profundidade e análise mais clara da realidade que se observa.

Assim, tanto a elaboração do produto, quanto sua aplicabilidade e análise dos resultados e discussões dos achados são ampliadas pela sua relação direta com o fenômeno em pesquisa.

Tem-se então, enquanto instrumentos de pesquisa bibliográfica para levantamento de dados: o currículo atual do Ensino Médio; o currículo do Novo Ensino Médio, a Base Curricular Nacional Comum (BNCC) do Ensino Médio; o Plano Nacional de Educação (PNE) e; a Lei das Diretrizes e Bases (LDB). Ainda, enquanto instrumentos de pesquisa relacionados ao estudo de caso: um teste para sondagem de conhecimentos prévios dos jovens do Ensino Médio acerca de noções da Contabilidade e; a Cartilha sobre noções de Contabilidade para o Ensino Médio.

A organização dos dados levantados, obedece, inicialmente, a organização de um referencial teórico e, posteriormente, à organização dos resultados do estudo de caso em si: um mapeamento sobre a sondagem das noções de Contabilidade para o mercado de trabalho; a aplicabilidade da cartilha, enquanto estrutura curricular complementar social para o Ensino Médio; uma nova avaliação após a implementação da referida estrutura curricular social e; discussões sobre a efetividade desta estrutura curricular complementar social para o Ensino Médio - se exitosa (ou não) para habilidades e competências necessárias para a 
profissionalização e enfrentamento em igualdade do mercado de trabalho. Por fim, busca-se ainda, comparar o currículo atual do Ensino Médio, com a proposta do Novo Ensino Médio (ainda que somente bibliográfica), bem como aos resultados obtidos empiricamente, com a aplicação da cartilha que visa preparo dos jovens para o mercado de trabalho e competitividade.

\begin{tabular}{|c|c|}
\hline ENSINO MÉDIO ATUAL & NOVO ENSINO MÉDIO \\
\hline BNCC engessada & BNCC Novo formato \\
\hline $\begin{array}{lr}\text { Conjunto de disciplinas pré- } & \text { er } \\
\text { estabelecidas, do repasse } & \text { do } \\
\text { conhecimento pronto aos alunos. } & \end{array}$ & $\begin{array}{l}\text { Permissão para que os jovens possam } \\
\text { escolher seus caminhos em relação às } \\
\text { áreas específicas e formação técnica e } \\
\text { profissional. }\end{array}$ \\
\hline $\begin{array}{l}\text { Carga Horária Anual } \\
\text { Formação Básica Geral } \\
\text { 2.50oh }\end{array}$ & $\begin{array}{l}\text { Carga Horária Anual } \\
\text { Formação Básica Geral } \\
\text { I.8ooh } \\
\text { Itinerários Formativos } \\
\text { I.20oh }\end{array}$ \\
\hline Componente Curricular Estático & Interdisciplinaridade \\
\hline $\begin{array}{l}\text { Formação Geral Básica com foco na } \\
\text { Universidade }\end{array}$ & $\begin{array}{l}\text { Formação Geral Básica forma para vida e os } \\
\text { itinerários tem foco Universidade e/ ou no } \\
\text { mundo do trabalho }\end{array}$ \\
\hline
\end{tabular}

Fontes: Resolução SEE no 4.234 23/ri/2019, Portaria no 521/21 e Cartilha do Novo Ensino Médio FENEP, p. 4

\section{ORGANIZAÇÃO CURRICULAR NO $1^{\circ}$ ANO EM 2022}

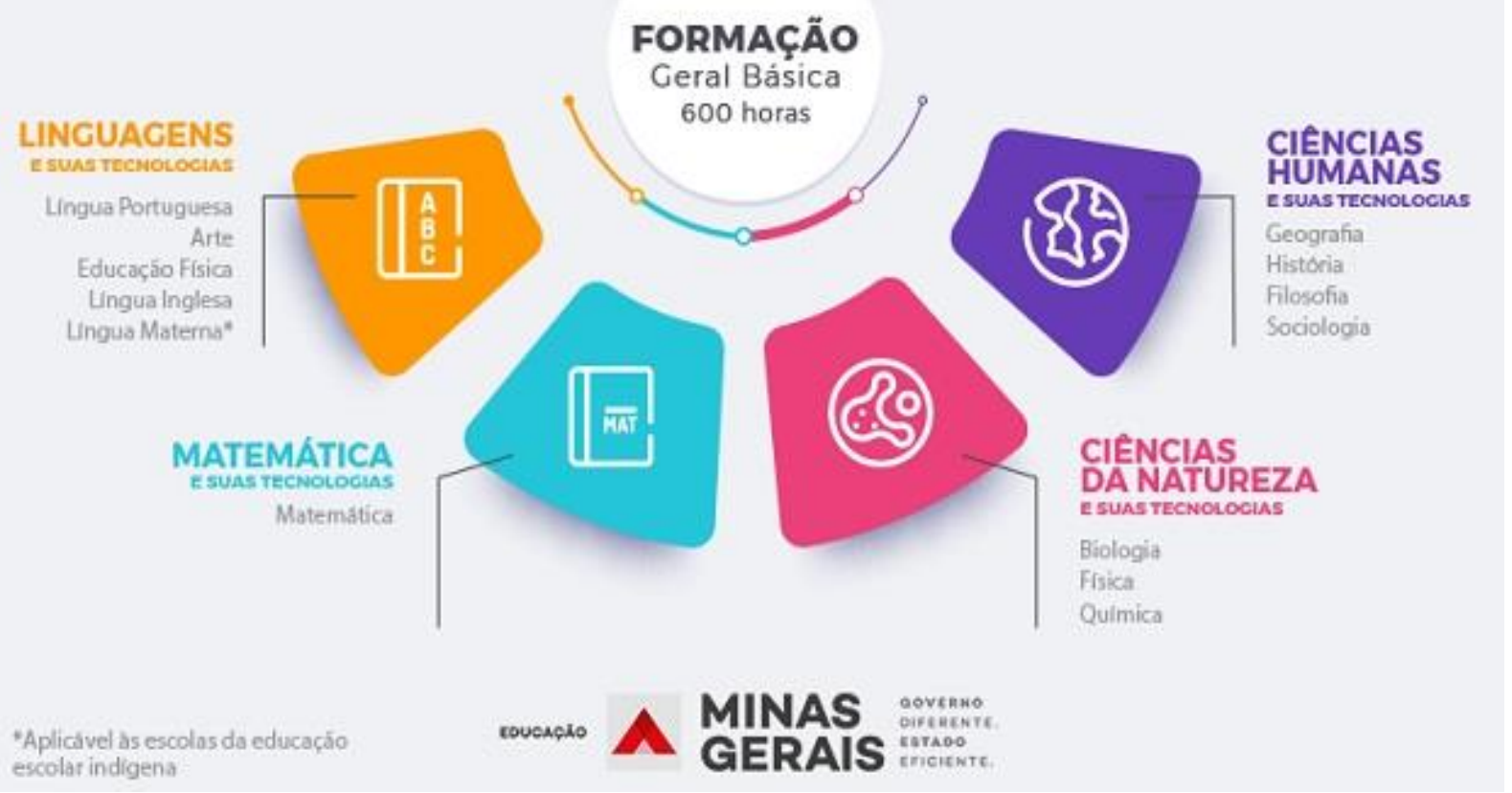




\section{ORGANIZAÇÃO CURRICULAR PARA 2022}

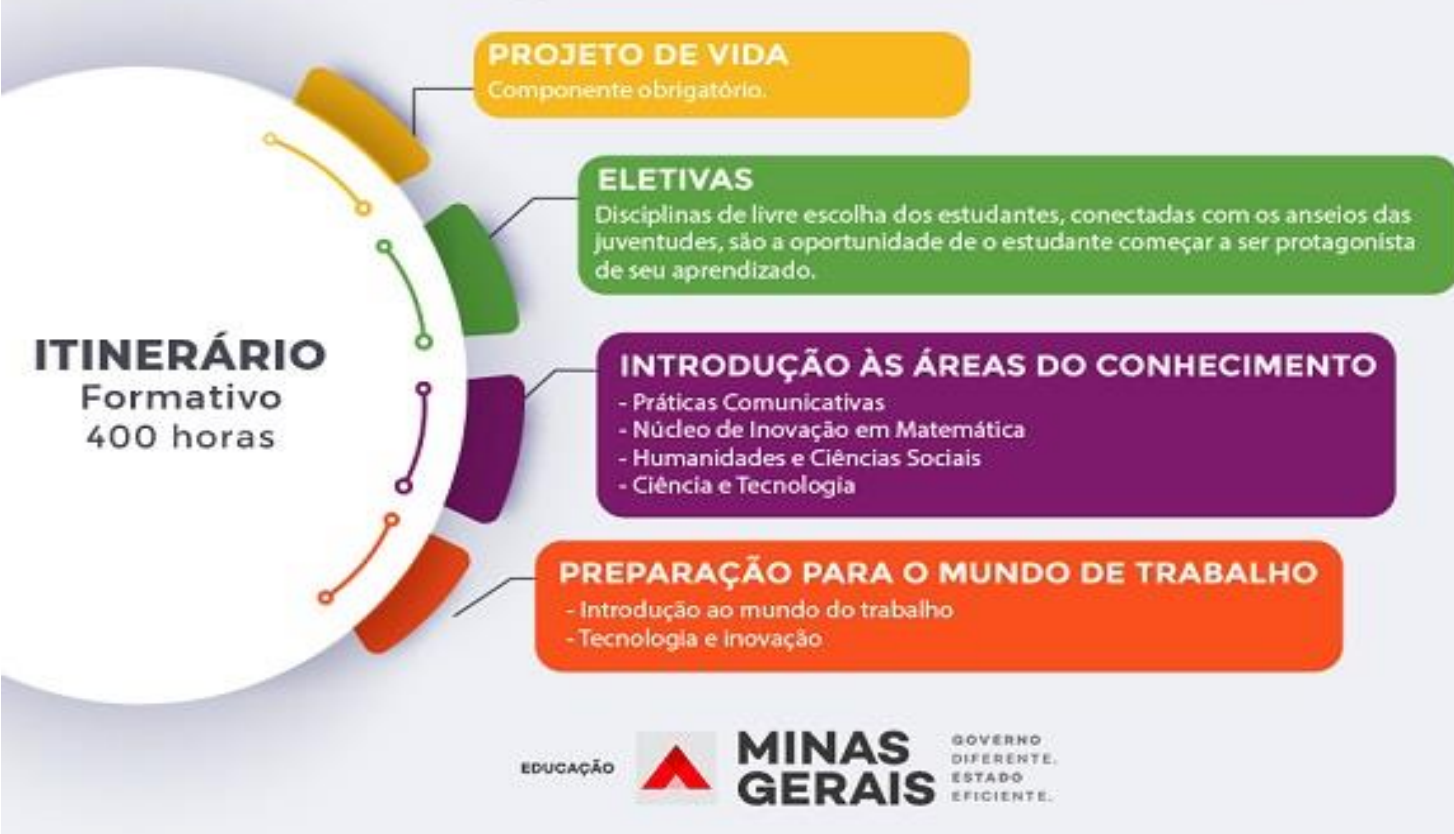

Fonte: https://www2.educacao.mg.gov.br/component/gmg/story/riso3-novo-ensino-medio-escolas-do-I-ano-do-ensino-medioimplementarao-a-proposta-em-2022.

\section{RESULTADOS E DISCUSSÃO}

Em nossas reuniões via google meet onde contamos com a participação da Direção, Especialistas de Educação, Professores e alunos, foi unânime que nosso tema e proposta vem para abrir novos caminhos e perspectivas aos jovens concluintes de ensino médio.

Também ficou claro que o atual currículo do Ensino Médio não proporciona e nem tem condições de proporcionar aos educandos um visão e capacitação para o mercado de trabalho.

Professores no atual cenário não possuem qualificação para preparar os educandos de Ensino Médio para o mercado de trabalho.

Espera-se que como advento da Portaria no. 521/21 os educandos possam ter um primeiro acesso às informações e formação para o mercado de trabalho.

\section{CONSIDERAÇÕES FINAIS}

A implementação de noções de contabilidade voltadas para o mercado de trabalho no Ensino Médio proporcionará aos educandos de escola públicas conceitos de cidadania, ética, uma matemática mais voltada para a vida financeira, como lidar com finanças pessoais, 
familiares, comerciais, etc.

Conhecimentos de tributos, direitos trabalhistas, conhecimentos administrativos proporcionando a eles uma chance de se ingressar no mercado de trabalho em profissões mais valorizadas. Aí sim o educando valorizará tudo o que foi a ele ensinado, eliminando o "fracasso escolar".

Desta forma o artigo 2o da Lei nº 9.394/96 - LDB no Título II Dos Princípios e Fins da Educação Nacional se concretizará.

A finalidade educacional se concretizará, principalmente aqueles que encerarão sua vida educacional naquele momento, mas com projeção e capacidade financeira suficiente para voltar aos estudos na graduação, pois, terão um cargo que corresponderá financeiramente para que isto ocorra.

\section{REFERÊNCIAS}

ALBUQUERCE, M. C. P.; MELO, M. L. N.; MOURA, F. A.; ALBUQUERQUE, M. L. S. Avaliação diagnóstica em Física no Ensino Médio. Brazilian Journal of Development, Curitiba, v.7, n.3, p. 30089-30098, mar. 2021.

ALMEIDA, A. C.; CARVALHO, E. C. S. Os comportamentos em relação ao autocuidado e empatia dos estudantes da unidade curricular Projeto de Vida e dos professores das Unidades Escolares-Piloto do Novo Ensino Médio no Distrito Federal, durante a pandemia da Covid-I9. Revista Com Censo: Estudos Educacionais do Distrito Federal, v. 8, n. 2, p. 2233, jun. 2021.

ALYRIO, R. D. Métodos e técnicas de pesquisa em Administração. Rio de Janeiro: Fundação CECIERJ, 2009.

ANDRADE, N. L.; SOUZA, T. N. A reforma do Ensino Médio (LEI 13.415/2017): o que pensam alunos e professores? Notandum, v. 23, n. 52, p. 41-59, jan./abr. 2020.

BERTRAND, Y. Teorias contemporâneas da educação. 2. ed. Lisboa: Instituto Piaget, 200 I.

BOHNEN, C.; OLIVEIRA, M. A. Cartilhas educativas para o ensino da Matemática no Projeto Conexão. Salão de Ensino e Extensão Inovação na Aprendizagem, 2018. Disponível em:

<https://online.unisc.br/acadnet/anais/index.php/salao_ensino_extensao/article/view/I8 664>. Acesso em: 5 jul. 2021.

BRASIL. Casa Civil. Lei no 9.394, de 20 de dezembro de 1996. Estabelece as diretrizes e bases da educação nacional. Disponível em: 〈http://www.planalto.gov.br/ccivil_03/leis/l9394.htm〉. Acesso em: Io jan. 202I.

BRASIL. Casa Civil. Lei no 13.415, de 16 de fevereiro de 2017. Disponível em: 
〈http://www.planalto.gov.br/ccivil_03/_ato2015-2018/2017/lei/li3415.htm〉. Acesso em: I0 set. 202I.

BRASIL. Diário Oficial da União. Portaria n. 521, de 13 de julho de 2021. Disponível em: 〈https://www.in.gov.br/en/web/dou/-/portaria-n-52I-de-I3-de-julho-de-202I-331876769>. Acesso em: ro set. 2021.

CIAVATTA, M.; RAMOS, M. Ensino Médio e educação profissional no Brasil: dualidade e fragmentação. Revista Retratos da Escola, Brasília, DF, v. 5, n. 8, p. 27-4I, 201 .

ESPINDULA, M.; LEITE, J. C. P.; PEREIRA, M. Z. C. O campo das políticas curriculares no Brasil: a trajetória da década de 9o. Espaço do Currículo, Paraíba, v. 5, n. I, p. I03-108, 2012.

FERRETI, C. J. A reforma do ensino médio e sua questionável concepção de qualidade da educação. Estudos Avançados, v. 32, n. 93, 2018.

FERRETTI, C. J.; SILVA, M. R. Reforma do Ensino Médio: Estado, currículo e disputas por hegemonia. Educação \& Sociedade, Campinas, v. 38, n. 139, p.385-404, abr./jun. 2017.

FRIGOTTO, G. A produtividade da escola improdutiva: um (re) exame das relações entre educação e estrutura econômica social e capitalista. São Paulo: Cortez, I989.

FRIGOTTO, G. (org.). Educação e crise do trabalho: perspectivas de final de século. Petrópolis: Vozes, 1999.

FRIGOTTO, G. Concepções e mudanças no mundo do trabalho e o ensino médio. In: FRIGOTTO, G.; CiAVATTA, M.; RAMOS, M. (Org.). Ensino Médio integrado: concepções e contradições. São Paulo: Cortez, 2005.

GENTILI, P. Educar para o desemprego: a desintegração da promessa integradora. In: FRIGOTTO, G. (org.). Educação e crise do trabalho: perspectivas de final de século. Petrópolis: Vozes, 1999.

GONÇALVES, S. D. R. V. Interesses mercadológicos e o 'novo' Ensino Médio. Revista Retratos da Escola, Brasília, DF, v. II, n. 20, p. 131-I45, 2017.

KRAWCZYK, N.; FERRETTI, C. J. Flexibilizar para quê? Meias verdades da "reforma". Revista Retratos da Escola, Brasília, DF, v. II, n. 20, p. 33-44, 2017.

LIBÂNEO, J. C. Tendências pedagógicas na prática escolar. In: Democratização da Escola Pública - a pedagogia crítico-social dos conteúdos. São Paulo: Loyola, 1992.

LINO, L. A. As ameaças da reforma desqualificação e exclusão. Revista Retratos da Escola, Brasília, DF, v. II, n. 20, p. 75-90, 2017.

MACIEL, A. C.; JACOMELI, M. R. M.; BRASILEIRO, T. S. A. Fundamentos da educação integral politécnica: da teoria à prática. Educação \& Sociedade, Campinas, v. 38, n. 139, p. 473-488, 2017. 
MELO, M. C. H.; CRUZ, G. C. Roda de Conversa: uma proposta metodológica para a construção de um espaço de diálogo no Ensino Médio. Imagens da Educação, v. 4, n. 2, p. $31^{-}$ 39, 2014 .

MORAN. J. A importância de construir Projetos de Vida na Educação. 2017. Disponível em: 〈http://www2.eca.usp.br/moran/wp-content/uploads/2017/1o/vida.pdf〉. Acesso em: 2I ago. 2021.

OBSERVTÓRIO DE EDUCAÇÃO, ENSINO MÉDIO E GESTÃO. BNCC: objetivos e desafios para a sua implementação. 2021. Disponível em: 〈https://observatoriodeeducacao.institutounibanco.org.br/em-debate/bncc-desafios-paraimplementacao?utm_source $=$ google \&utm_medium $=$ cpc\&utm_campaign $=11358183974 \& u \mathrm{tm}$ _content $=$ II 4499843858\&utm_term $=$ base $\% 2$ oda\%2oeduca\% $\% \mathrm{C}_{3} \% \mathrm{~A} 7 \% \mathrm{C}_{3} \% \mathrm{~A} 30 \&$ gclid $=\mathrm{CjwK}$ CAjwhaaKBhBcEiwA8acsHDdYvIfpcimix7dECZXtb3WFPN85DZEH553fEKQlunqPm Q_SoMLS2xoCi74QAvD_BwE>. Acesso em: ro set. 2021.

OLIVEIRA, R. Empresariado industrial e educação brasileira: qualificar para competir. São Paulo: Cortez, 2005.

OLIVEIRA, R. Precarização do trabalho: a funcionalidade da educação profissional. Revista Diálogo Educacional, Curitiba, v. 15, n. 44, p.247-266, jan./abr. 2015.

OLIVEIRA, R. O Ensino Médio e a inserção juvenil no mercado de trabalho. Trab. Educ.

Saúde, v. I6, n.I, abr. 2018. Disponível em: <https://www.scielo.br/j/tes/a/XDscrRPhM9Yk493QMMgWjxC/?format=html\&lang= pt $>$. Acesso em: 28 jun. 2021.

OLIVEIRA, R. O Ensino Médio e a precocidade do trabalho juvenil. Educ. Rev., Curitiba, v. 34, n. 67, p. 177-197, fev. 2018.

OLIVEIRA, S. R.; BATISTA, S. S. S. Juventude e formação profissional no contexto das reformas do Ensino Médio e das Diretrizes Curriculares Nacionais (1971-2017). Rev. Espaço do Currículo, João Pessoa, v.II, n.I, p. 84-93, jan./abr. 2018.

PIOLLI, E.; SALA, M. Reforma do Ensino Médio e a formação técnica e profissional. Revista USP, São Paulo, n. I27, v.I, p. 69-86, 2020

POCHMANN, M. O emprego no desenvolvimento da nação. São Paulo: Boitempo, 2008.

RAMOS, M. N. Impacto da educação para o trabalho na sociedade. Boletim Técnico do SENAC, Rio de Janeiro, v. 4o, n.3, p. 6-17, set/dez.2014.

RIBEIRO, M. L. P. C.; ARRUDA, V. P.; BOMFIM, J. Entre dilemas, sonhos, projetos e vida: o Novo Ensino Médio e o itinerário de Formação Técnica e Profissional no Centro de Ensino Médio Integrado do Gama no Distrito Federal. Revista Com Censo: Estudos Educacionais do Distrito Federal, v. 8, n. 2, p. 55-66, jun. 202I. 
RODRIGUES, W. O currículo escolar aumentando desigualdades sociais: o caso da educação pública brasileira. Revista Educação, Pobreza e Desigualdades Sociais: Interlocuções entre Currículo e Ensino, v. 6 n. I8, p. 85-91, 2019.

SANT'ANNA, I. M. Por que avaliar? como avaliar? - critérios e instrumentos. 3. ed. Petrópolis: Vozes, 1995.

SIlVA, F. C. S.; CARVAlHO, A. C. S. A.; LIGABO, M.; RODRIGUES, D.; RODRIGUES, R. C. L. B. Proposta para Implementar Avaliação Formativa no Ensino Médio. Ciênc. Educ., Bauru, v. 26, n.I, 2020.

SILVA, M. R.; SCHEIBE, L. Reforma do ensino médio: pragmatismo e lógica mercantil. Revista Retratos da Escola, Brasília, DF, v. II, n. 20, p. 19-31, 2017.

SOARES, M. M. N.; SIMÕES, G. A. M. Histórico e processo de construção do Novo Ensino Médio no âmbito do Distrito Federal. Revista Com Censo: Estudos Educacionais do Distrito Federal, v. 8, n. 2, p. 130-134, jun. 2021.

SOUZA, D.C.C; VAZQUEZ, D.A. Expectativas de jovens do ensino médio público em relação ao estudo e ao trabalho. Educ. Pesqui., São Paulo, v. 4I, n. 2, p. 409-426, abr./jun. 2015.

TARTUCE, G. L. B. P et al. Desafios do ensino médio no Brasil: iniciativas das secretarias de educação. Cadernos de Pesquisa, v.48 n.ı68, 2018.

VILHENA, A. P. M. P. Escola e futuro no capital simbólico da juventude em Belém: um estudo de representações sociais. Tese (Doutorado em Educação) - Universidade Estácio de Sá. Rio de Janeiro, 2019.

ZANELlA, L. C. H. Metodologia de pesquisa. 2. ed. Florianópolis: Departamento de Ciências da Administração/UFSC, 201 I. 